\title{
A review of maternal mortality at Jimma Hospital, Southwestern Ethiopia
}

\author{
Asheber Gaym
}

Abstract: A retrospective review of hospital maternal deaths at Jimma Hospital, Southwestern Ethiopia, covering the period from September 1990 to May 1999 was conducted with the objectives of determining the overall maternal mortality rate, observing trend of maternal mortality during the period, and identifying major causes of maternal mortality. The overall maternal mortality rate for the period was 1965 maternal deaths per 100000 live births ranging from 1636 to 2332 deaths per 100000 live births with an overall trend showing no decrease. Ruptured uterus $(33.2 \%)$ was the major cause of death with unsafe abortion responsible for $26.8 \%$ of all cases. Overall, hemorrhagic complications of pregnancy, sepsis and hypertensive disorders were responsible for $94.9 \%$ of all maternal deaths. Analysis of trends of major causes showed deaths due to ruptured uterus to be increasing over the years. Obstructed labor is found to be directly or indirectly responsible for $45.53 \%$ of all maternal deaths mainly affecting the primigravida and the grand multipara (44.9\%). Concentrating on the provision of peripartum care to this subgroup of mothers is suggested as one possible strate oy to effect rapid reduction in overall maternal mortality within the foreseeable future. [Ethiop. J. Health Dev. 2000;14(2):215-223]

\section{Introduction}

Maternal mortality is one of the major public health problems challenging the medical community especially in developing countries. WHO recently estimated that 580,000 maternal deaths occur annually, $99 \%$ of them in the developing world $(1,2)$. Maternal deaths account for less than $1 \%$ of deaths among women of reproductive age group in the developed world, but the corresponding figure for developing countries is close to $25-30 \%$ $(3,4)$. Maternal mortality is important not only because it represents the single mostpreventable cause of death among women of reproductive age group, but also because it is an important contributing factor to infant and child mortality (5). Current maternal mortality rate estimates for the developing world are 270/100000 for Latin America, 420/100,000 for Asia and 640/100000 for Africa (6).

Various approaches are used to obtain data on maternal mortality. Preferably, community

Department of Gyn-Obs, Faculty of Medicine, Addis Ababa University, Addis Ababa, Ethiopia based data from birth and death registers where these are routinely and universally documented are the most reliable sources. In countries where such registration is not routine (which includes most of the developing world), various indirect methods of obtaining maternal mortality data are used, such as the sisterhood method, networking method of obtaining community-based maternal mortality data, and the verbal autopsy approach to identify causes of matemal deaths $(7,8,9)$. Data obtained from health institutions can also give a reliable estimate of community maternal mortality at institutions where health care coverage is optimal. Since they may also represent severe complicated cases from the community they may give some idea of major causes of maternal mortality in. the community, especially the urban community. At times they may also be the only source of information concerning health related data as it may be difficult to obtain information regarding community-based data.

A five year retrospective review of maternal mortality at Black Lion Hospital in Addis Ababa by Yoseph and Kifle (10) found a 
maternal mortality rate of $960 / 100000$ with complications of abortion being the major cause $(22.2 \%$ of the maternal deaths). Institutional maternal mortality data obtained from researchs done in the African settings found mortality rates ranging from $90 / 100000$ $1525 / 100000$ live births with the major cause of maternal mortality being direct causes, such as septic abortion, puerperal sepsis, henormage during pregnancy, obstructed labor and ruptured uterus. A smaller percentage was caused by indirect causes, mainly infections in pregnancy, like viral hepatitis, malaria, and pneumonia $(1,12,13)$. Ali reviewed maternal mortality at dimma Hospital for a lifteen-month period during $1991 \ldots 1992$ (14). Ne found the rate to be $2600 / 100,000$ live births. Septic abortion was the commonest cause accounting for $29 \%$. Ruptured uterus and postpartum hemorrhage were responsible for the remainder of direct maternal deaths.

In view of the importance of maternal mortality as a major public health problem, it is important to conduct studies to define its magnitude, identify major causes, and predisposing factors and changing trends over time so as to come up with preventive strategies. The objectives of this study were to identify the hospital maternal mortality ratio, identify major causes of maternal deaths, look for changing trends in maternal mortality over the years under review if any and identify predisposing or risk factors for the occurrence of maternal deaths.

\section{Methods}

A retrospective description of maternal deaths that occurred at the gynecology and obstetrics department of Jimma Hospital from September 1990 to May 1999 was undertaken. Jimma Hospital, a teaching hospital affiliated to the Jimma Institute of Health Sciences for the last 15 years, has had the services of at least one obstetrician-gynecologist during the period reviewed in this study. The hospital is located three hundred and forty kilometers from the capital Addis Ababa. It has $\mathbf{2 1}$ maternity beds excluding five labor suite coaches and is staffed by five obstetricians, two midwives, and six nurses. Mean delivery at the unit during the study period was 1342 per year. It has in effect been the referral unit for Obs-Gyn cases that come from within $400 \mathrm{~km}$ or more radius area around the hospital. Due clearance for the conduct of the study was obtained from the Department of Gyn/Obs, Jimma Institute of Health Sciences and from the Research and Publication Office of the Institute. Permission was also obtained from the director of Jimma Hospital to obtain the records of the maternal deaths.

The record books of the maternity ward and gynecology wards were reviewed during the study period for all maternal deaths that occurred and this was cross -checked with the hospital archives for accuracy. A standard questionnaire was used to document relevant socio-demographic and clinical variables on the maternal deaths. Labor ward delivery records were analyzed to compute total births and live births during the study period. Results were computed from September to August of 19901998. For 1999 it is only inclusive of September 1998 to May 1999.

Both direct maternal deaths (death of the mother during or within forty two days of delivery from causes directly related to pregnancy or its management) and indirect maternal deaths from accidental, or incidental causes not directly related to pregnancy as defined by WHO, were included in the study. Non-maternal deaths not related to pregnancy or its complication were excluded from the study. Maternal deaths that may have occurred in the medical and surgical departments were difficult to obtain due to the non-specificity of the records as to the pregnancy status of the female patients admitted to those wards. Data were coded and analyzed using Microsoft window 97 Excel program.

In the analysis of the distance of referral unit from Jimma Hospital, those that came from Jimma town proper were identified as form Jimma town and those from outside the town 
were analyzed according to the distance from the town's periphery. Distance was estimated using the official map of the area.

\section{Results}

There were 235 maternal deaths, 11,961 live births and 1461 still births from September 1990 to May 1999 making the overall maternal mortality rate for the ten year period 1965 per 100,000 live births. The lowest recorded was 1636 per 100,000 live births in 1992 and the highest was 2332 per 100,000 live births in 1990 (Table 1). Eventhough there are variations in the yearly maternal mortality rates, there is no overall increase or decrease in the trend during the study period (Figure 1).

Age and party analysis of maternal mortality (Table 2) shows that $34.5 \%$ of maternal deaths are in the parity group $2-4$. However, $50.2 \%$ of all maternal deaths occurrred among primiparas and in the grand multipara, which are recognized high risk groups for poor pregnancy outcome. Of all maternal deaths, $22.1 \%$ occurred among teenage mothers and $37.5 \%$ among mothers over 30 years of age. Nevertheless $40.42 \%$ of all maternal deaths have occurred in the age group of 20-29.

\section{Maternal mortality rate}

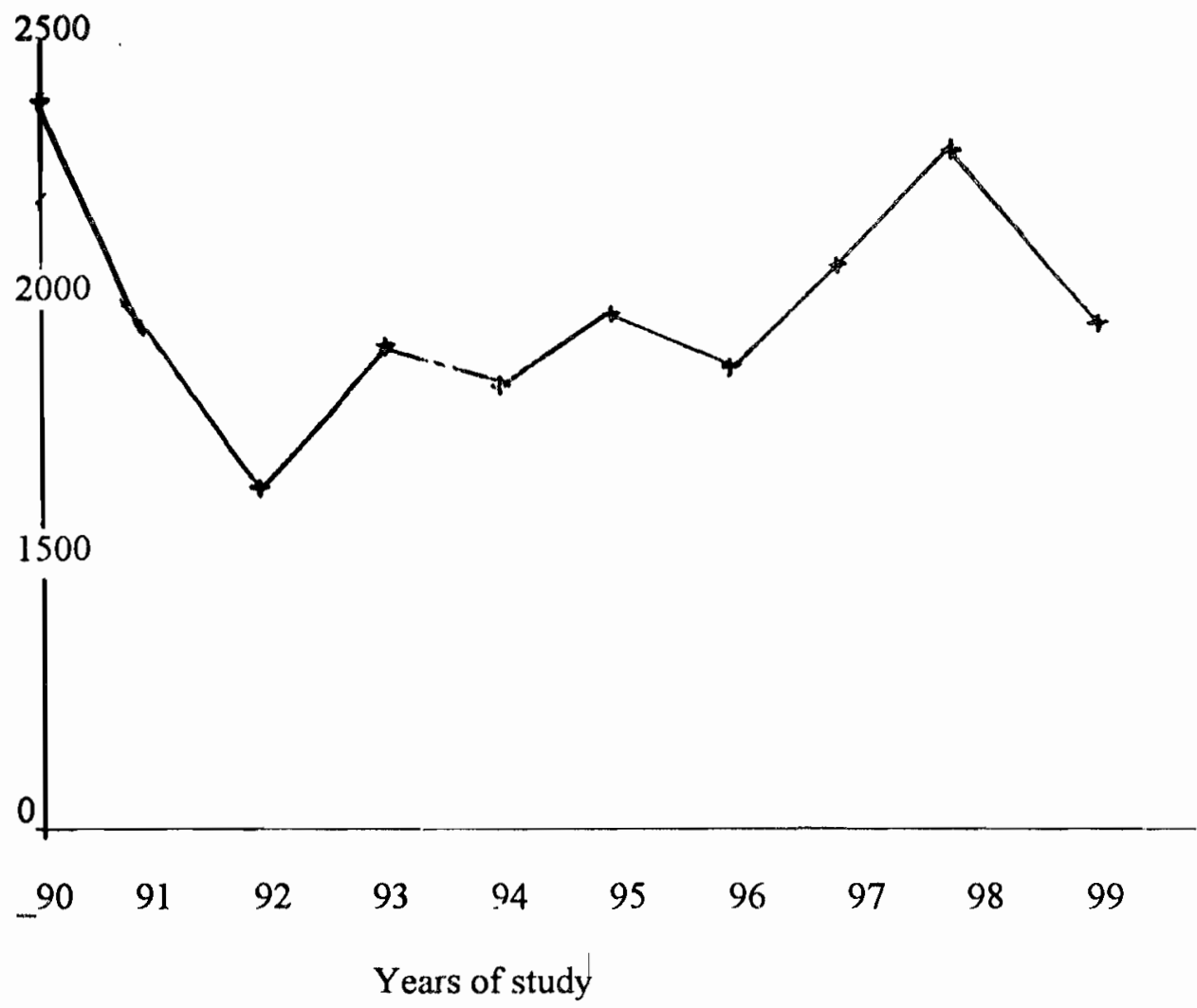

Figure 1: Trend of maternal mortality during $1990-1999$ 
Table 1: Trend of maternal mortality, Jimma Hospital, 1990 - 1999

\begin{tabular}{llccl}
\hline Year & Maternal deaths & Total deliveries & Live births & $\begin{array}{l}\text { Maternal mortality per 100000 live } \\
\text { births }\end{array}$ \\
\hline 1990 & 26 & 1200 & 1115 & 2331.8 \\
1991 & 20 & 1095 & 1031 & 1939.8 \\
1992 & 15 & 999 & 917 & 1635.8 \\
1993 & 15 & 930 & 822 & 1824.8 \\
1994 & 21 & 1290 & 1184 & 1773.6 \\
1995 & 21 & 1320 & 1106 & 1898.7 \\
1996 & 25 & 1680 & 1422 & 1758.3 \\
1997 & 35 & 1920 & 1710 & 2046.8 \\
1998 & 35 & 1710 & 1476 & 2303.3 \\
1999 & 22 & 1290 & 1178 & 1867.6 \\
\hline Total & 235 & 13425 & 1196 & 1965.0 \\
\hline
\end{tabular}

Of all maternal deaths $94.9 \%$ were direct maternal deaths while only $5.1 \%$ were due to causes not directly related to pregnancy. Of the indirect maternal deaths, malaria was responsible for four deaths, infectious hepatitis for three, cardiac disease, diabetes, intestinal obstruction, pneumonia, and pulmonary tuberculosis being responsible for one maternal death each (Table 3). Ruptured uterus (33.2\%) constituted the single commonest cause of maternal mortality but if post-caesarian sepsis $(12.3 \%)$ is considered together with ruptured uterus, obstructed labor becomes the single most important cause of maternal deaths responsible for $45.5 \%$ of the total. Most mothers who died following caesarian section were caesarian sections performed for patients referred for obstructed labor from long distances.
Overall, septic complications of pregnancies are responsible for $40 \%$ of maternal deaths, hemorrhagic complications for $11.1 \%$, and eclampsia for $3.8 \%$ of all maternal deaths excluding deaths from obstructed labor.

Figure 2 shows the trend of specific major causes of maternal mortality as a proportion of all maternal deaths yearly during the study period. Ruptured uterus has been the commonest cause of maternal death in later years and has not shown a decreasing trend throughout the study period. However, unsafe abortion which was the commonest cause of death during the first half of the study period has shown a decreasing trend in the latter half of the study period being responsible for much lesser proportion of maternal deaths than ruptured uterus. Puerperal sepsis and

Table 2: Age and parity distritution of maternal deaths, Jimma Hospital, 1990-1999

\begin{tabular}{lccccc}
\hline \multicolumn{5}{c}{ Parity } \\
\hline Age & 0 & 1 & $2-4$ & $\geq 5$ & Grand Total \\
$<20$ & 12 & 32 & 7 & 1 & $52(22.1 \%)$ \\
$20-24$ & 13 & 8 & 14 & - & $35(14.9 \%)$ \\
$25-29$ & 8 & 6 & 27 & 10 & $60(25.5 \%)$ \\
$30-34$ & 2 & 1 & 20 & 21 & $49(20.9 \%)$ \\
$35-39$ & 1 & - & 13 & $6(13.6 \%)$, & $6(2.6 \%)$ \\
$40-44$ & - & - & - & 1 & $1(0.4 \%)$ \\
$>45$ & - & $62(26.4 \%)$ & $81(34.5 \%)$ & $56(23.9 \%)$ & $235(100)$ \\
\hline Grand total & $36(15.3 \%)$ & & & 6 & 2 \\
\hline
\end{tabular}




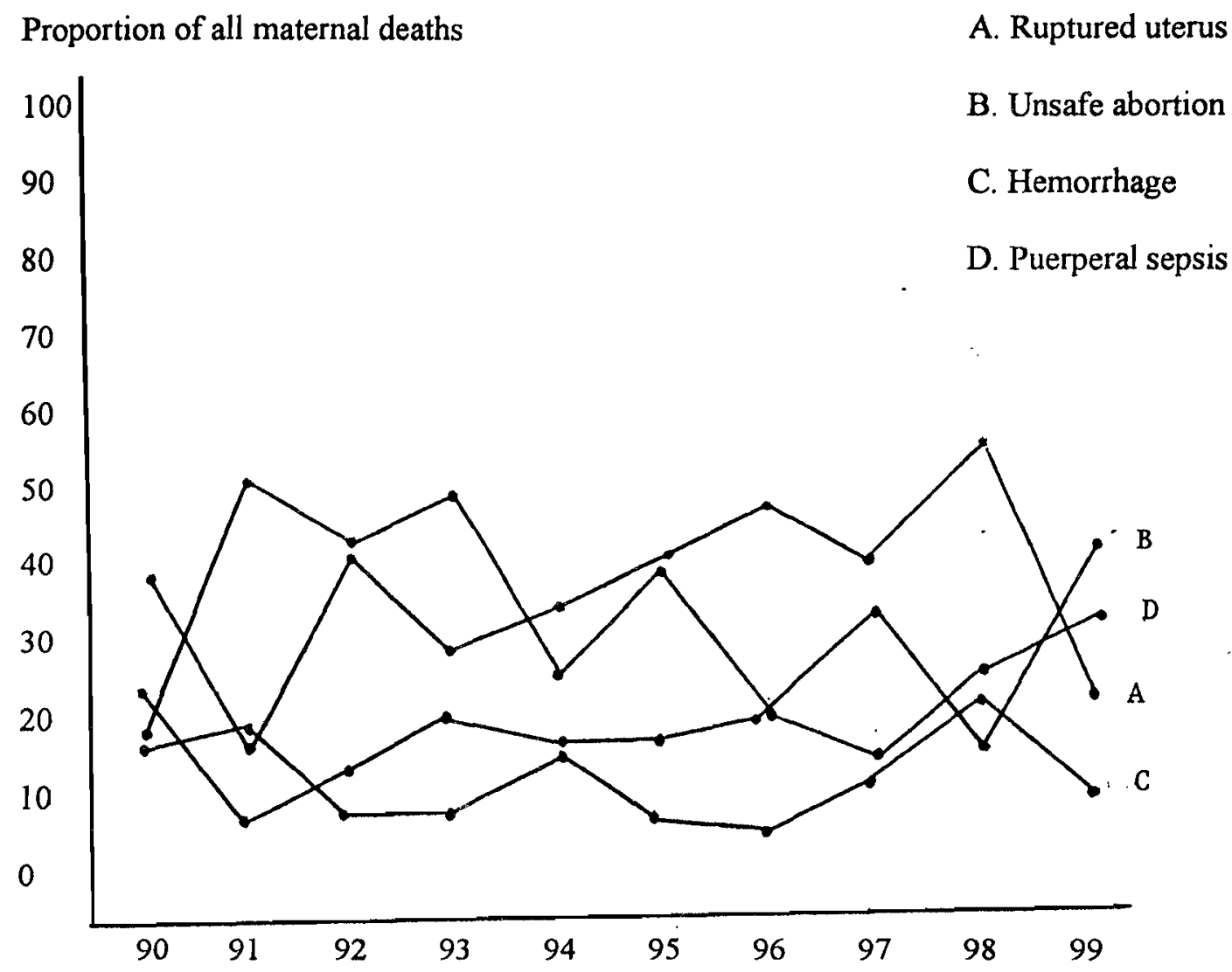

Figure 2: Trend of major causes of maternal mortality as a proportion of all maternal deaths.

Table 3: Maternal mortality by specific causes of death, Jimma Hospital, 1990-1999

\begin{tabular}{lcl}
\hline Caue of Death & No & $(\%)$ \\
\hline Ruptured uterus & 78 & $33.2 \%$ \\
Unsafe abortion & 63 & $26.8 \%$ \\
Puerperal sepsis & 47 & $20.0 \%$ \\
Post partum hemorhage & 17 & $7.2 \%$ \\
Eclampsia & 9 & $3.8 \%$ \\
Antepartum hemorrhage & 6 & $2.5 \%$ \\
Ectopic pregnancy & 3 & $1.3 \%$ \\
Indirect manternal deaths & 12 & $5.1 \%$ \\
\hline Total & 235 & $100.0 \%$ \\
\hline
\end{tabular}

hemmorrhagic complications of pregnancy (antépartum hemorrhage, postpartum hemorrhage, and ectopic pregnancy) have been responsible for a lower proportion of maternal deaths throughout the study period having a stable trend.
Age and parity analysis for specific causes of maternal mortality showed that the majority of death due to unsafe abortion (31.7\%) occurred among teenage mothers (Table 5). Ruptured uterus death were evenly distributed among the para $2-4$ and grand multiparous mothers. But the primipara were not immune to rupture accounting for $7.7 \%$ of the cases. Almost all eclamptic deaths occurred in primiparous mothers, $37.5 \%$ of whom were teenagers.

Table 6 depicts the distribution of maternal death by road distance from stated address of mothers from Jimma Hospital and from outside the town of the mothers who died. Seventy six point nine percent of the mothers came from within a distance of 100 kilometres from 
Table 4: Trend of major causes of maternal mortality as a proportion of all deaths during 1990 - 1999.

\begin{tabular}{lllllll}
\hline & $\begin{array}{l}\text { Ruptured } \\
\text { uterus }\end{array}$ & $\begin{array}{l}\text { Unsafe } \\
\text { abortion }\end{array}$ & Hemorrhage & $\begin{array}{l}\text { Puerperal } \\
\text { sepsis }\end{array}$ & Others & Total \\
\hline $1990(\%)$ & $10(38.5)$ & $5(19.2)$ & $4(15.4)$ & $6(23.0)$ & $1(3.9)$ & $26(100)$ \\
$1991(\%)$ & $3(15.0)$ & $10(50.0)$ & $3(15.0)$ & $1(5.0)$ & $3(5.0)$ & $20(100)$ \\
$1992(\%)$ & $6(40)$ & $6(40)$ & $1(6.7)$ & $2(13.3)$ & - & $15(100)$ \\
$1993(\%)$ & $4(26.7)$ & $7(46.7)$ & $1(6.7)$ & $3(20)$ & - & $15(100)$ \\
$1994(\%)$ & $7(33.3)$ & $5(23.8)$ & $3(14.3)$ & $3(14.3)$ & $3(4.3)$ & $21(100)$ \\
$1995(\%)$ & $8(38.0)$ & $7(33.3)$ & $1(4.8)$ & $3(14.3)$ & $3(14.3)$ & $21(100)$ \\
$1996(\%)$ & $11(44.0)$ & $5(20.0)$ & $1(4.0)$ & $5(20.0)$ & $3(12)$ & $25(100)$ \\
$1997(\%)$ & $12(34.2)$ & $4(11.4)$ & $4(11.4)$ & $11(31.4)$ & $4(11.4)$ & $35(100)$ \\
$1998(\%)$ & $13(38.2)$ & $8(23.5)$ & $6(17.6)$ & $5(14.7)$ & $2(6.9)$ & $34(100)$ \\
$1999(\%)$ & $4(18.2)$ & $6(27.2)$ & $2(9.0)$ & $8(36.4)$ & $2(9.1)$ & $22(100)$ \\
\hline Total & $78(33.2)$ & $63(26.8)$ & $26(11.1)$ & $47(20)$ & $21(8.9)$ & $235(100)$ \\
\hline
\end{tabular}

N.3. Others indlect maternal deaths and caser of aclampsta

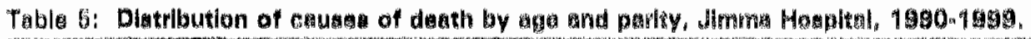

\begin{tabular}{|c|c|c|c|c|c|c|c|}
\hline & $\begin{array}{l}\text { Unsafo } \\
\text { Abortion }\end{array}$ & $\begin{array}{l}\text { Auprurad } \\
\text { uterus }\end{array}$ & $\begin{array}{l}\text { Puepporal } \\
\text { sepsis }\end{array}$ & Haftorbluge & Ectampos| & $\begin{array}{l}\text { Indirgot } \\
\text { doaths }\end{array}$ & Total \\
\hline \multicolumn{8}{|l|}{ Age } \\
\hline $15-19$ & $20(31.7 \%)$ & $5(6.4 \%)$ & $13(27.7 \%)$ & $7(26.9 \%)$ & $3(37.5 \%)$ & $2(16.7 \%)$ & 50 \\
\hline $20-24$ & $19(30.2 \%)$ & $4(5.1 \%)$ & $5(10.6 \%)$ & $5(19.2 \%)$ & $2(25 \%)$ & $2(16.7 \%)$ & 37 \\
\hline $25-29$ & $14(22.2 \%)$ & $24(30.8)$ & $9(19.1 \%)$ & $5(19.2 \%)$ & $4(37.5 \%)$ & $5(41.7 \%)$ & 61 \\
\hline $30-34$ & $7(11.1 \%)$ & $23(29.5 \%)$ & $12(25.5 \%)$ & $5(19.2 \%)$ & - & $2(16.7 \%)$ & 49 \\
\hline $35-39$ & $3(4.7 \%)$ & $18(23.1 \%)$ & $6(12.8 \%)$ & $4(15.4 \%)$ & - & $1(8.3 \%)$ & 32 \\
\hline $40-44$ & - & $3(3.8 \%)$ & $2(4.3 \%)$ & - & - & - & 5 \\
\hline$>45$ & - & $1(1.3 \%)$ & - & - & - & - & 1 \\
\hline $\begin{array}{l}\text { Total } \\
\text { Parity }\end{array}$ & $63(100 \%)$ & $78(100 \%)$ & $47(100 \%)$ & $26(100 \%)$ & $9(100 \%)$ & $12(100 \%)$ & 235 \\
\hline 0 & $36(57.1 \%)$ & - & - & - & 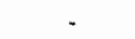 & - & 36 \\
\hline 1 & $17(26.9 \%)$ & $6(7.7 \%)$ & $19(40.4 \%)$ & $12(46.2 \%)$ & $8(87.5 \%)$ & $1(8.3 \%)$ & 63 \\
\hline $2-4$ & $10(15.9 \%)$ & $36(46.2 \%)$ & $20(42.6 \%)$ & $7(26.9 \%)$ & $1(12.5 \%)$ & $.8(66.7 \%)$ & 82 \\
\hline$\geq 5$ & & $36(46.2 \%)$ & $8(17.0 \%)$ & $7(26.9 \%)$ & 0 & $3(25.0 \%)$ & 54 \\
\hline Total & $63(100 \%)$ & $78(100 \%)$ & $47(100 \%)$ & $26(100 \%)$ & $9(100 \%)$ & $12(100 \%)$ & 235 \\
\hline
\end{tabular}

Jimma hospital, $18.4 \%$ came from within 100 400 kilometres distance and in $4.7 \%$ of the cases the registered address of the mothers could not be identified either on a map or by community elders.

Nearly $80 \%$ of all the maternal deaths did not have antenatal care (Table 7). When antenatal care status is assessed for specific causes of maternal death, the difference is not much for eclampsia, puerperal sepsis, and haemorrhagic complications. Difference in antenatal care attendance status on the other hand is more in mothers who died due to unsafe abortion and ruptured uterus.
Table 6: Distribution of maternal deaths by distance of address from Jimma hospital in kilometers, Jimma Hospital

\begin{tabular}{ll}
\hline $\begin{array}{l}\text { Distance in kilometers from } \\
\text { Jimma town }\end{array}$ & $\begin{array}{l}\text { \% of all maternal } \\
\text { deaths }\end{array}$ \\
\hline Jimma town & $43 / 235(18.3 \%)$ \\
$1-24$ & $34 / 235(14.5 \%)$ \\
$25-49$ & $56 / 235(23.6 \%)$ \\
$50-74$ & $39 / 235(16.6)$ \\
$75-99$ & $7 / 235(2.9 \%)$ \\
$100-199$ & $25 / 235(10.6 \%)$ \\
$200-299$ & $18 / 235(7.7 \%)$ \\
$300-400$ & $2 / 235(.9 \%)$ \\
address not traced & $11 / 235(4.7)$ \\
Total & $235 / 235(100)$ \\
\hline
\end{tabular}


Table 7: Antenatal care status of maternal deaths by cause of death

\begin{tabular}{lccc}
\hline Diagnosis & Yes & No & Total \\
\hline Ruptured uterus & 7 & 71 & 78 \\
Unsafe abortion & 1 & 62 & 63 \\
$\begin{array}{l}\text { Puerperal sepsis } \\
\text { Hemarrage }\end{array}$ & 18 & 29 & 47 \\
Indirect maternal & 10 & 16 & 26 \\
dsaths & 4 & 8 & 12 \\
Eclampsia & 4 & 5 & 9 \\
\hline Total & 4.4 & 191 & 235 \\
& $(18.7 \%)$ & $(81.3 \%)$ & $(100 \%)$ \\
\hline
\end{tabular}

\section{Discussion}

This study gives an overview of the maternal mortality status in a rural hospital setting as it stands at the turn of the century. Notwithstanding the fact that health institution" based maternal mortality rates are considerably higher than community rates because of the high risk status of mothers delivering at hospitals, the overall maternal mortality rate of 1965 per 100,000 live births is considerably higher than the 960 per 100,000 hospital-based maternal mortality rates found in Addis Ababa by Yoseph and Kifle (13) and Frost in 1980 $(780$ per 100,000$)(15)$. As a rural hospital 340 kilometers away from Addis Ababa and handling referrals from 300 or more kilometers radius, it is not surprising that the rate is much higher than that found in hospitals in Addis Ababa. High as it is, the rate may in fact be an underestimate of the actual rate as some women may die without the diagnosis of pregnancy, others may die due to puerperal complications after discharge from the hospital and indirect maternal deaths occurring in other wards of the hospital have not all been accounted for.

Of all the maternal deaths, 81 (34.5\%) occurred in parity group two to four. This agrees with other studies done under similar settings. However the majority of maternal deaths $(50.2 \%)$ occurred among the primipara and the grand multipara, making these parity groups a possible target group for intervention to reduce maternal mortality. The main cause of deaths in this group of mothers is obstructed labor resulting in ruptured uterus and sepsis.

Direct causes of maternal death related to hemorrhage, sepsis or hypertension complicating pregnancy remain to be major causes of maternal mortality as demonstrated in similar studies from the third world. Unlike the two hospital-based mortality studies done in Black Lion Hospital by Yoseph and Frost which found ruptured uterus to be the third commonest cause of maternal mortality, ruptured uterus is responsible for $33.2 \%$ of maternal mortality making obstructed labor an important cause of maternal deaths. Of these deaths related to obstructed labor $26.8 \%$ occurred among primiparous and grand multiparous mothers. Two hundred forty four cases of ruptured uterus were treated at Jimma Hospital during the same period making the case fatality rate $78 / 244(31.96 \%)$ one of the highest reported for the condition. Of all mothers with ruptured uterus $44 / 78(56.5 \%)$ were admitted in moribund state with hypovolemic shock.

Of all mothers $192 / 235$ ( $80.7 \%$ ) were referred from outside Jimma town. Of these $45 / 235$ (19.1\%) had to travel a distance of $100-400$ kilometers seeking aid at the hospital. Of the mothers who came from outside Jimma town, 136/235(57.8\%) came from a distance of less than 100 kilometers from the town. Improving the referral system within this distance range by improving transportation facilities like ambulance provision from peripheral clinics may be one feasible strategy to address the problem.

Maternal mortality has been identified as a major public health problem in the developing world and various strategies to reduce it have been proposed and implemented by national governments and WHO for almost three decades. The primary health care strategy, the safe motherhood initiative, and later, the mother-baby package are a few of these. Despite the enormous effort put into it, WHO estimates indicate that maternal mortality rate has in fact increased in the last ten years from 
500,000 to 580,000 deaths per year throughout the developing world. (5) The present study has not shown a decreasing trend in the rate and, in fact, for some causes of maternal mortality, such as ruptured uterus, an increasing trend was observed. Assessing the trend at health institutions requires analysis of staffing, budgetary conditions, quality of pre and in-service training, and quality of antenatal care provided during the study period. The trend of maternal mortality has not shown any change during the ten years reviewed during which period there has not been a significant change in staffing. Although for a few years the hospital has functioned with only one gynecologist for the most part it has had the services of three to five gynecologists providing twenty four hour service.

That currently proposed strategies such as post-abortion care, family planning provision, and provision of emergency obstetric care will reduce maternal mortality is indisputable. However when seen in the light of limited resources available to developing countries like Ethiopia, these options can at best be viewed as long term strategies of addressing the enormous problem. Pregnancy and delivery however remain to be a day-to-day hazardous event in the life of some women in the developing world. It is clear that short-term strategies with clearly oriented goals need to be implemented hand in hand with long-term strategies and goals of reducing maternal mortality. This study has shown that obstructed labor is responsible for up to $45 \%$ of maternal deaths mainly in the primiparous and the grandmultiparous woman. Strategies directed at provision of peripartum care focusing the limited resources on these groups of mothers may be one of the possible short-term strategies to effect a significant reduction in maternal mortality in the near future.

\section{Acknowledgement}

I would like to express my heartfelt thanks to Dr Bahru Mekete and Dr Feiruz Surur of the department of Gyn- Obstetrics and Dr Tesfaye
Getaneh, Research and Publication Officer of the Jimma Institute of Health Sciences for their help during the conduct of this study. I also thank Dr Gerbi Duguma, Medical Director of Jimma Hospital for giving me permission to use the archives for the study.

\section{References}

1. Hoberg U. Maternal mortality-a world wide problem. Int J Gynacol-Obstet. 1985; 23(6):463-70.

2. Boema JT. Levels of maternal mortality in developing countries. Stud-Fam-Planning. 1987;18(4):213-21.

3. Boema $T$. The magnitude of maternal mortality problem in Sub Saharan Africa. Soc Sci Med. 1987;24(6):550-8.

4. Rosen FA. Maternal mortality in developing countries. J AM A. 1989;262(3):376-9.

5. Rosen F. New estimates of maternal mortality. Weekly-epidemiological-Record. 1996. (Mar) 29;71(13):97-100.

6. Harrison KA. Tropical obstetrics and Gynacology 2. Maternal mortality. Trans R Soc Trop Mio Hyg, 1989;83(4):449-53.

7. Graham W, Brass W, Snow RW. Estimating maternal mortality-Sisterhood method. Stud-Fam-Plann. 1989;20(3)125-35. 8. Kane T T, El-Kad AA, Saleh S, Hage M, Slanbuk $J$, Pollio $Z$. Maternal mortality in Egypt: mágnitude, cases and prevention. Stud Fam planning. 1992;23(1):34-37.

9. Hernandez $B$, Chininas $J$, Romero $M$, Langer A. Estimating matemal mortality in the rural areas of Mexico: the application of an indirect demographic method. Gynecologie Obstetric Mexico. 1990;23(2):34-38.

10. Yoseph S, Kifle G. A six year review of maternal mortality in a teaching hospital in Addis Ababa, Ethiop Med J, 1988;26:1 15-120. 11. Kwast BE, Stevens JA. Viral hepatitis as a major cause of maternal mortality in AA, Ethiopia. Int-J-gynaecol-Obstet. 1987;25(2):99106.

12. Kampikaha A, Irrig SI. Risk factors for maternal mortality at five Kampala hospitals 1980-1986. Int J Epidemiol. 1990;19(4): 11168. 
13. Adetoro OO. Maternal mortality-a 15 year survey at the University of Itonn. Teaching Hospital, Ellipsis, Nigeria Int J Gynaecol Obstet. 1987;25(2):93-8.

14. Ali Y. Analysis of maternal deaths in Jimma Hospital, southwestern Ethiopia. Brief
Communication, Ethiop Med J, 1994;32:132134.

15. Frost $O$. Maternal and perinatal deaths in an Addis Ababa hospital, 1980. Ethiop Med J, 1982;26:125-127. 